\title{
Cedeca Interlagos: Fotografia e educomunicação para o desenvolvimento humano
}

André Bueno

Fotógrafo, educador e especialista em Gestão da Comunicaşão pela Escola de Comunicações e Artes da Universidade de São Paulo.

E-mail: andre@andrebueno.com.br

Resumo: Propõe-se, dentro dos estudos de comunicação, qualificar o impacto das atividades realizadas pelo ponto de cultura e Centro de Defesa da Criança e Adolescente - Cedeca Interlagos - junto de seu público, bem como analisar especialmente os efeitos dos projetos de oficinas fotográficas desenvolvidos na entidade e em outras, coordenados pelo autor deste artigo. Como material relevante para nossos estudos, recuperamos, através de entrevistas, a visão de alguns participantes das atividades realizadas entre o período 2007 e 2012. Sustentado por diversos olhares, mas sendo costurado a partir da ótica de um fotógrafo e gestor da comunicação, este trabalho tem por finalidade discutir, num plano geral, a fotografia e a Educomunicação para o desenvolvimento humano.

Palavras-chave: CEDECA Interlagos; Defesa da Criança e do Adolescente; fotografia; imagem; intervenção urbana.
Abstract: The proposal of this paper is, within the scope of Communication Studies, to examine the impact of the activities developed by the CEDECA Interlagos (Cultural center for Children and Teenagers support) on their target public, as well as to analyse the result of the projects and photography workshops developed in the center, coordinated by the author of this paper. As a relevant material for our research, we use the interviews conducted with the participants of the workshops between 2007 and 2012, analyzing their point of view. This paper is based on diverse perspectives, but it is mainly constructed according to a vision of a photographer and communication manager, and has as an objective to discuss the Photography and the Educommunication for the human development.

Keywords: CEDECA Interlagos; Children and teenagers support; photography; image; urban intervention.

\section{APRESENTAÇÃO}

O presente artigo, resultado de um trabalho de pesquisa qualitativa cujo tema é "Fotografia e Educomunicação para o desenvolvimento humano", tem como proposta estimular a discussão sobre os estudos de comunicação no Centro de Defesa da Criança e

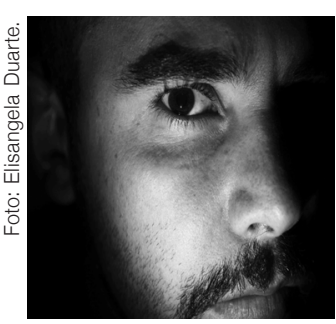

André Bueno 
comunicação \& educação • Ano XVIII • número 1 • jan/jun 2013

1. O Cedeca Interlagos é uma ONG de pequeno porte, fundada em 1999, e pertencente à Associação Nacional do Centros de Defesa da Criança e Adolescente (ANCED). De origem e âmbito regional municipal (SP), o Centro de Defesa dos Direitos da Criança e do Adolescente atua apostando contra toda desesperança e cinismo do senso comum, no potencial da infância e da juventude, buscando dignidade humana a partir da defesa dos direitos da criança, do adolescente e do jovem, construindo experiências de resistência no meio das inúmeras favelas e loteamentos clandestinos das regiões da Capela do Socorro, Grajaú e PareIheiros, na Zona Sul de São Paulo. Seu estatuto se coloca no papel de: defesa dos direitos da criança e do adolescente; atendimento a crianças e adolescentes em situação de vulnerabilidade; promover a proteção jurídico-social, na lógica de proteção integral, na ótica de políticas públicas com construção e participação popular, além de atuar na área da assistência social e também ser ponto de cultura.

2. COSTA, Maria Cristina Castilho. Educação, imagem e mídias. São Paulo: Cortez, 2005, p. 82.
Adolescente - Cedeca ${ }^{1}$ Interlagos, tentando entender os efeitos dos projetos "Oficinas de fotografia e educação" - realizados ali (2009) e em outras instituições de Paraisópolis e Grajaú (2007-2012) - sobre seu o público, em suas formas de expressão, compreensão da sociedade, na construção de suas imagens de mundo e em seu desenvolvimento humano.

Também buscamos compreender a visão de participantes engajados em outras atividades culturais (grafite, hip-hop, artes plásticas etc.) realizadas pelo Cedeca, no que se refere às contribuições que estas trouxeram para suas vidas e também quanto às interpretações sobre o que a instituição representa para estes jovens, buscando entender o impacto das atividades da organização na comunidade.

No decorrer deste trabalho, a fotografia é tratada como elemento capaz de transformar a realidade e os sujeitos. Como fundamento teórico, buscou-se,

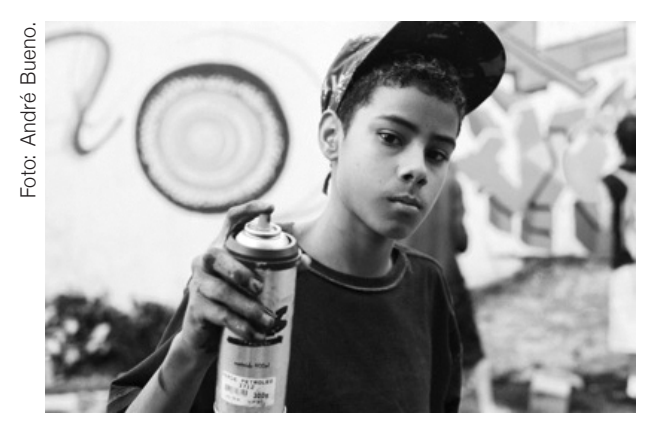

Evento do Dia do Grafite, organizado pelo Cedeca Interlagos, em 2009. além da compreensão sobre o mundo da fotografia, referenciado por pesquisadores deste campo, desenvolver uma pesquisa a partir da perspectiva das ciências da comunicação, nos permitindo uma compreensão menos ingênua do cenário midiático que vivenciamos atualmente. Dentro deste contexto, enfatizaram-se as possibilidades fotográficas como meio de comunicação para o conhecimento.

\section{A FOTOGRAFIA COMO ELEMENTO TRANSFORMADOR DA REALIDADE E DO SUJEITO}

Buscamos colaborar para a reflexão em torno da fotografia e de outras linguagens visuais, acreditando terem potencial para a comunicação interpessoal e servirem como "fonte de conhecimento, descobertas, atenção e memória"'. Elas são também favoráveis para nos expressarmos, são estimuladoras para o diálogo entre adultos, crianças, fotógrafos, comunicadores, organizações e, ainda, por que não dizer, para a comunicação com o poder público. $\mathrm{O}$ universo de produção das imagens tem potencial para contribuir com o desenvolvimento humano e com a percepção e fortalecimento de identidades.

Nosso objetivo não se restringe aos estudos sobre processos estritamente produtivos ou questões estéticas. Buscamos contribuir para o entendimento do universo das imagens e do sistema de sua produção, na medida em que favorecem o desenvolvimento humano, mediados pela interposição de um conjunto de signos (fotos, ficções e outras narrativas poéticas) que possibilitam a transformação de realidades e dos sujeitos que nela estejam inseridos.

Nós escolhemos a fotografia como linguagem visual de referência para a reflexão, por seu importante papel na sociedade e capacidade de estabelecer 
relações entre os sujeitos e o mundo. No entanto, não descartamos que existam outras linguagens como o cinema, as artes plásticas e outras produções visuais favoráveis à análise neste mesmo sentido. Mas a fotografia tem se mostrado uma linguagem inteligente, na medida em que vem estimulando o conhecimento e o olhar crítico sobre a realidade, através de composições que nos fazem pensar, que nos intrigam e nos enquadram dentro do que foi registrado. Em outras palavras, segundo Roland Barthes, a fotografia "é subversiva, não quando aterroriza, perturba ou mesmo estigmatiza, mas quando é pensativa”3.

Entendemos que a linguagem fotográfica, dentre outras linguagens visuais, é capaz de expandir nossa consciência para além da capacidade que temos de perceber e interpretar cotidianamente, sem a utilização dos meios culturais.

A ação de aprender a olhar para o mundo se dá pelo constante exercício de compô-lo e recompô-lo. O modo como cada pessoa se interessará em acessá-lo trata-se essencialmente de uma escolha, uma espécie de alternativa que, quando amadurecida, pode possibilitar a origem de um novo estilo de vida, uma nova comunicação. Os conflitos existentes na realidade nem sempre precisam ou podem ser enfrentados diretamente. As imagens, linguagens e processos de produções culturais podem ser os mediadores entre sujeito

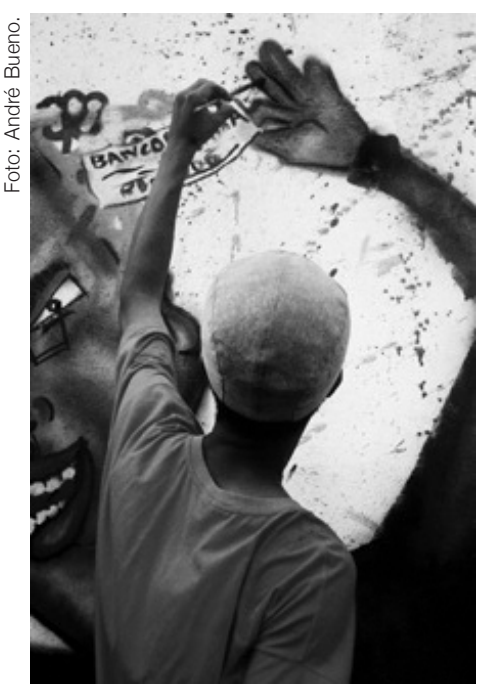
Retrato de Thiago Moraes (Tigone) e sua pintura. e cotidiano.

Este trabalho reflete sobre a possibilidade de aplicação da fotografia como um meio de comunicação favorável para a emancipação, e também sobre o estímulo do olhar e a aquisição de conhecimento, incluindo ainda suas possíveis aplicações na contemporaneidade que digam respeito a uma educação dialógica.

Acreditamos que a discussão em torno da fotografia, em sua relação com a educação, contribuirá para a formação de sujeitos e gestores que cultivem imagens de mundo menos ingênuas. Um estímulo para esse processo se dá a partir do momento em que uma "fotografia educomunicativa" for inserida na sociedade e nas instituições de ensino através de uma ótica humana, cultural, emancipadora e igualitária. Nesse sentido, segundo Costa, em seu trabalho Educação, imagem e mídias:

(...) a opção por uma educação que valoriza a educação pela e para a imagem não se faz em nome de uma ação pedagógica menos disciplinada ou mais espontaneísta, mas em busca de um entendimento mais efetivo do mundo e de uma comunicação mais abrangente e inclusiva. (...) Houve um tempo no qual a imagem era um mero adereço na educação, na divulgação e na produção literária, porém hoje os mais diversos campos do saber, da produção e da comunicação humana se apoiam na linguagem visual e na representação imagética $(. . .)^{4}$.

3. BARTHES, R. A câmara clara. Rio de Janeiro: Ed. Nova Fronteira, 1984, p. 62.

4. COSTA, op. cit., p 35 e 36. 
Levando em consideração o atual universo midiático, tecnológico e o impacto das mídias no cotidiano, no campo da educação, bem como sua influência direta na vida dos jovens, além da pluralidade existente quanto aos modos de "produção, circulação e recepção do conhecimento e da informação" ${ }^{\text {, o campo }}$ da Educomunicação nos sugere novas formas de ensino-aprendizagem e possíveis caminhos para uma educação dialógica e participativa.

A linguagem fotográfica foi escolhida propositadamente como meio de comunicação e referência de expressão visual, tendo os projetos de fotografia e educação como uma das várias alternativas educativas para o acesso a outras realidades sociais que favoreçam o desenvolvimento humano e estimulem olhares críticos e discussões em torno das possibilidades de defesa de direitos das crianças e dos adolescentes nos centros de defesa (Cedeca's).

\section{A PESQUISA}

Contribuíram para esta pesquisa participantes dos projetos de "Oficinas de fotografia e educação", coordenados e assessorados pelo autor deste trabalho, no período de 2007 a 2012, intitulados: projeto fotográfico "Um Olhar"6(2007 a 2009); projeto "Retratos, um Click para a Educação" (2010), e projeto "D'Olho"» (2011). Além de alguns jovens que participaram de outras atividades culturais desenvolvidas pelo Cedeca Interlagos, entre o período de 2001 e 2012, sendo que alguns deles foram convidados a trabalhar no Centro de Defesa e se tornaram educadores.

Os três projetos de "Oficinas de fotografia e educação" utilizaram a fotografia como linguagem para o conhecimento, aplicada ao cotidiano e ao campo da educação. Os projetos foram desenvolvidos em uma escola pública da cidade de São Paulo e em organizações do terceiro setor, voltadas às comunidades de Paraisópolis e no Grajaú, na Zona Sul de São Paulo.

Seus objetivos foram trabalhar a fotografia - em oficinas e saídas fotográficas - junto do público adolescente, utilizando-a como um meio de comunicação

5. SIMÕES, 2011

6. <http://www.umolhar. org/>.

7. Vídeo e publicação com fotos do projeto. Disponível em: <http://www.vimeo com/19507696>; <http:// www.flickr.com/photos/retratosumclickparaeducacao/ sets/72157625203676762/>

8. Vídeo sobre o projeto "D'Olho". Disponível em: <http://vimeo. com/33716710> e blog $<$ http://projetodeolho. blogspot.com.br/>. favorável para a educação, a pesquisa, a crítica e a expressão artística, iniciando jovens na área da fotografia, incentivando o exercício de olhares críticos, a participação popular e a produção cultural coletiva de cunho documental.

$\mathrm{O}$ intuito inicial desta pesquisa com públicos diferentes, os jovens participantes das atividades oferecidas pelo Cedeca e aqueles especificamente das oficinas de Fotografia, partiu de duas hipóteses: 1) verificar, com os participantes das oficinas fotográficas realizadas no Cedeca e em outras instituições, o quanto a fotografia e as vivências trocadas durante as oficinas influíram em suas formas de expressão, de olhar e também na formação de suas imagens de mundo; 2) verificar, com jovens participantes de atividades culturais realizadas pelo Cedeca, o impacto destas atividades e o quanto estas atingiram os objetivos a que a organização se propõe. 
O universo da amostra foi composto de 31 pessoas entrevistadas, sendo que vinte delas correspondem ao público das "Oficinas de fotografia e educação" e onze participaram de outras atividades culturais desenvolvidas pelo Cedeca, como oficinas de grafite, estêncil, vídeo, eventos de hip-hop, debates e outras.

A pesquisa qualitativa foi desenvolvida a partir de duas perspectivas diferentes para cada grupo amostral, e com dois focos distintos, utilizando questionários como roteiro de entrevista semiestruturada, composto de questões diferenciadas para o público participante das atividades do Cedeca, e outro para os participantes dos projetos de "Oficinas de fotografia e educação". As entrevistas foram gravadas em áudio e transcritas.

\section{SOBRE O IMPACTO DA FOTOGRAFIA E VIVÊNCIAS DURANTE AS OFICINAS FOTOGRÁFICAS}

Os jovens entrevistados, em sua maioria com nível médio de instrução e faixa etária entre 19 e 21 anos, chegando a até 30 anos, apontaram de maneira quase consensual a questão da mudança do olhar e o desenvolvimento de uma visão crítica sobre o mundo como os fatores que mais aprenderam durante as oficinas fotográficas. Porém, aspectos como conquistar um olhar que valoriza a região onde vivem, o ganho de autoconfiança e o desenvolvimento do aprendizado técnico também foram apresentados como fatores importantes:

A oficina nos ajudou a nos descobrir, a ver o mundo de outra forma e analisar mais as coisas. A fotografia me possibilitou a descobrir a mim mesma e o que eu quero realmente. O curso de fotografia mudou nossa perspectiva de vida (Elaine Braga).

Dentre os vinte entrevistados, somente um relatou que atualmente não percebe a influência quanto à forma de ver o mundo, tempos depois de ter participado das oficinas. Os demais afirmaram que ainda hoje notam mudanças nesse sentido, ao observarem o cotidiano em geral, e ainda disseram ter passado a notar mais detalhes no dia a dia, além de perceberem que agora enquadram o mundo em cenas, imagens, fotos, luzes e sombras.

Observamos uma coincidência nos relatos feitos pelo público das atividades do Cedeca Interlagos, e aqueles vindos das oficinas de fotografia: ambos relataram

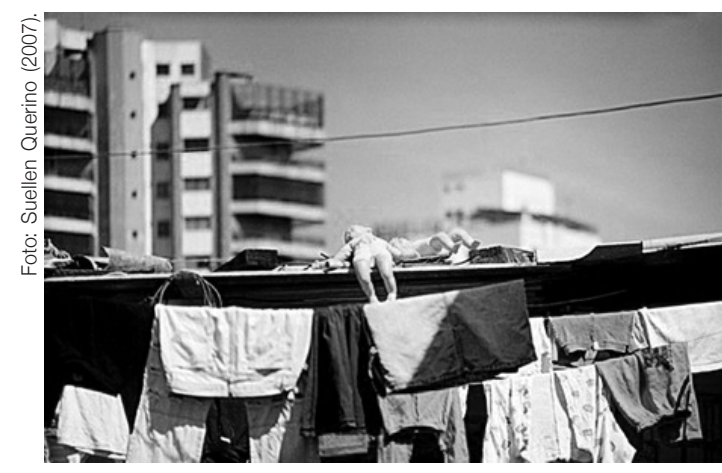

ter desenvolvido uma visão crítica sobre o mundo e ter conseguido despertar um olhar que valoriza a região onde vivem.

Praticamente todos os participantes (dezenove deles) afirmaram sentir uma influência positiva em suas formas de expressão, a partir das oficinas de fotografia. Reforçando essa ideia, 
comunicação \& educação • Ano XV|l| • número 1 • jan/jun 2013

grande parte deles diz ter passado a expressar melhor seus sentimentos, a se comunicar com outras pessoas de forma mais eficiente, a adotar a fotografia como meio de expressão artística e, curiosamente, uma parte significativa dos entrevistados relata ter uma influência sobre sua forma de expressão escrita, além da fotográfica.

Há um consenso quanto a assumir que o aprendizado vivenciado durante as atividades envolvendo fotografia foi positivo, a ponto de todos os entrevistados afirmarem que aconselhariam outras pessoas a participarem da mesma experiência. Dentre os entrevistados, oito deles sugeriram que esse tipo de trabalho continuasse voltado ao público adolescente, outros oito disseram que ele deveria ser realizado para um público sem restrição etária, e os demais apontaram a necessidade de se desenvolver um projeto com crianças.

O trabalho desenvolvido com fotografia foi interpretado pela maior parte dos participantes como um caminho para a construção de vivências e para o desenvolvimento individual. A possibilidade de conhecer novas pessoas e novos lugares, ser uma opção favorável para a distração e relaxamento, promover o desenvolvimento humano, a partir do desenvolvimento de um senso crítico e do contato com a realidade, contribuir para o amadurecimento do olhar e para a construção de um ponto de vista sobre o mundo. Além da oportunidade de contar histórias e construir vivências a partir de imagens, contribuir para a formação do caráter, oferecer um novo meio de comunicação e fomentar o desenvolvimento de outras linguagens, como a escrita, por exemplo, foram apontados como fatores importantes para o desenvolvimento humano.

Depois de terem participado das oficinas fotográficas, praticamente todos os entrevistados começaram a perceber mudanças em sua maneira de ver e enquadrar o mundo. Além disso, passaram a conseguir descrever seus olhares antes e depois da experiência da fotografia. Diante disso, assumimos que é impossível descrevermos um olhar que não seja o nosso, pois estaremos amarrados sempre a uma perspectiva, a um olhar capaz de distorcer outro olhar. Nossa saída é, talvez, atribuir nossa visão limitada sobre os diversos olhares apresentados na perspectiva de "antes e depois da fotografia", baseando-nos nos diálogos e depoimentos apresentados pelos entrevistados no decorrer deste projeto, resultando em uma espécie de sobreposição ou mistura de olhares do pesquisador e pesquisado.

Desse modo, podemos indicar algumas características associadas aos olhares anteriores à fotografia e aqueles posteriores, classificando-os e atribuindo-lhes sentidos apoiados em depoimento de vários entrevistados. Assim, notamos olhares fechados, inexistentes, vazios, preconceituosos, quadrados, olhares em preto e branco, olhares turvos, ou mesmo uma visão sem olhar. Quanto aos olhares depois da prática da fotografia, transformaram-se em olhares panorâmicos, questionadores, nítidos, novos, criativos, distintos, coloridos, ampliados e mais críticos. Segundo alguns dos entrevistados:

O mundo era em preto e branco, sem cores, sem sombra, sem contrastes, via o que todos viam e o que a mídia queria que fosse visto. Depois da fotografia, 
o meu senso crítico se tornou mais afiado, o mundo ganhou novas formas e cores. Tudo passou a ter um significado que se encaixava como uma peça de quebra-cabeça. A fotografia foi superimportante para ter um novo olhar sobre o cotidiano (Thiago Carneiro).

Após o período de realização das oficinas fotográficas, considerando apenas os vinte entrevistados da amostra, oito deles seguem dando os primeiros passos para a profissionalização na área da fotografia, sendo que alguns já realizaram trabalhos remunerados, obtiveram apoio da Secretaria de Cultura para o desenvolvimento de projetos fotográficos, estão atuando como educadores ou fazendo algum curso de aperfeiçoamento.

Outros dez entrevistados disseram continuar fotografando no dia a dia, como hobby, registrando suas famílias, e até produzindo ensaios pessoais, como trabalho de cunho documental e artístico. Um único jovem que relatou não mais praticá-la, Danilo Sousa, afirma: "não tiro mais fotos e nem atuo em nenhum trabalho como esse, mas a experiência que tive com a fotografia jamais esquecerei”.

Portanto, para além da pretensão fotográfica direcionada ao profissional, pode-se notar que, mais relevante do que isso, foi a importância dada às vivências e novas imagens de mundo construídas. Uma discussão sob a ótica de uma possível profissionalização de jovens e adultos no campo da fotografia pode ser uma segunda e complexa discussão a ser realizada.

\section{SOBRE O IMPACTO DAS ATIVIDADES DO CEDECA INTERLAGOS JUNTO A SEU PÚBLICO}

A maior parte dos entrevistados havia estabelecido o primeiro contato com o Centro de Defesa a partir de eventos realizados em espaços públicos, principalmente durante intervenções urbanas de grafite e rap realizadas na rua. Durante as entrevistas, foi apontada também a influência que alguns artistas e educadores locais exerceram por meio do convite para participação nas atividades, dentre eles Jerry Batista, Helder Oliveira, Pato Cacá e Wellington Neri (Tim).

Dos onze entrevistados, oito afirmaram que haviam conhecido o Cedeca a partir de alguma atividade relacionada ao grafite e a eventos de intervenções

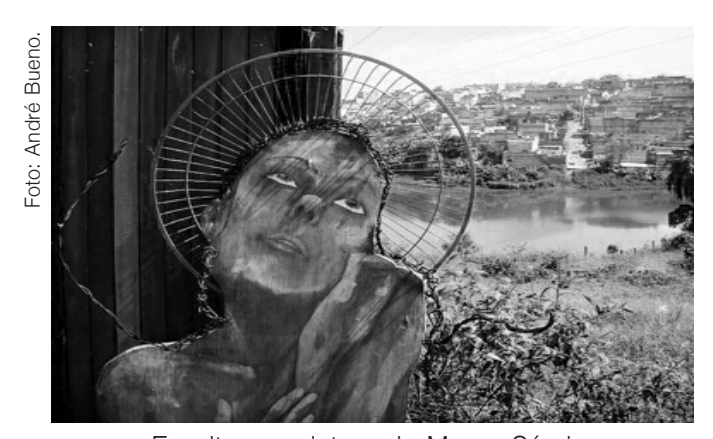

Escultura e pintura de Mauro Sérgio. urbanas. Na sua maioria integraram mais de uma atividade promovida pela organização, geralmente de hip-hop, exposições de arte, manifestações sobre direitos das crianças e dos adolescentes, eventos esportivos, oficinas fotográficas e outras.

Para a maioria dos entrevistados, aspectos como ser reconhecido 
comunicação \& educação • Ano XV|l| • número 1 • jan/jun 2013

artisticamente, a realização de trabalhos em grupo, formar laços de amizade e as vivências pessoais trocadas foram considerados primordiais para que gostassem das atividades. Dentre as contribuições mais importantes que os entrevistados indicaram levar para suas vidas, temos especialmente o desenvolvimento de um espírito coletivo e de um olhar crítico. No mesmo sentido, também disseram ter aprendido a valorizar e respeitar o próximo e o bairro onde vivem, bem como relataram um despertar maior de consciência sobre seus direitos e deveres.

Um dos períodos mais marcantes na história da organização, como nos relata Wellington Neri, o Tim, foi aquele em que a instituição entregou ao Estado as medidas socioeducativas, através de um ato interventivo em frente ao Parque do Ibirapuera. Neste momento a organização passou a encarar a "intervenção urbana" como uma prática mais frequente, indo ao encontro de outros jovens em seu convívio social no ambiente da rua. Segundo Tim:

Me marcou a época em que entregamos as medidas socioeducativas ao governo através de um ato em frente ao Parque do Ibirapuera, no qual construímos uma cela em que ficamos 48 horas presos. Acho que aquele momento foi um momento forte em que o Cedeca começou a perceber que intervenção urbana com arte repercute e funciona. Até então nós só fazíamos oficinas de break, grafite e outras, mas depois disso passamos a fazer várias intervenções (Wellington Neri).

Percebe-se um interesse muito forte dos jovens participantes das atividades do Cedeca em realizar mudanças na sociedade por meio da arte e da cultura, da intervenção urbana, que é geralmente estimulada ou sugerida pela própria instituição. Nessa mesma direção, observamos que a organização também exerceu grande influência sobre os entrevistados quanto a suas formas de expressão. Eles relatam ter desenvolvido, a partir das vivências propostas pelo Cedeca, um maior senso de liberdade de expressão, principalmente através de linguagens visuais como o grafite, o rap e outras formas de intervenção.

A maioria dos entrevistados identifica o Cedeca Interlagos como um ponto de cultura e como um espaço aberto para o jovem, sendo uma organização sempre disposta a dialogar e apoiar o protagonismo juvenil. Mas parte significativa dos entrevistados também apontou para o aspecto de que o Cedeca não é mais o mesmo e que atualmente a organização não tem feito intervenções com atividades realizadas na rua e outras atividades em geral que favoreçam a expressão. Uma pequena parte dos entrevistados também reclamou do fato de nos últimos tempos terem encontrado a organização com as portas fechadas, sugerindo que estas estejam abertas, e que se passe a colocar em prática o estúdio de produção existente.

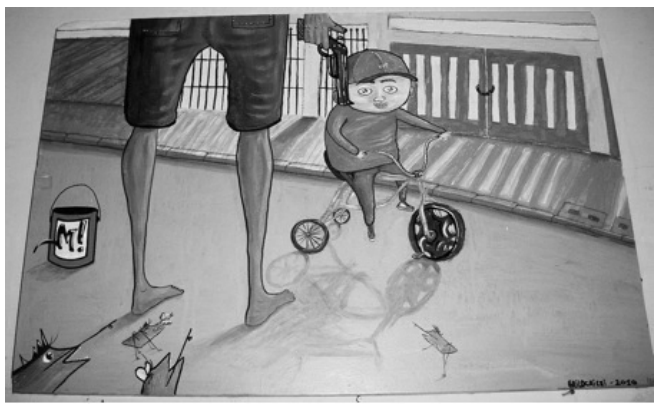

Desenho de Gelson Salvador Those (reprodução). 


\section{CONSIDERAÇÕES FINAIS}

Baseado nas pesquisas e análises de dados levantados a partir das entrevistas, foi possível observar que todas as atividades foram realizadas com êxito e bem-aceitas pelo público. Este relatou ter um despertar de olhares críticos e a adoção de outras formas de ver, compreender, se expressar, interagir e até se inserir no mundo, mediado principalmente pelas linguagens fotográficas, do grafite e do rap, a partir do contato com a fotografia e com o Centro de Defesa.

Afirmamos isso nos apoiando em inúmeros depoimentos consistentes, provindos de dezenas de diálogos com tipos de público diferentes, participantes de atividades até certo ponto distintas, mas que se aproximam num único sentido, fizeram uso da fotografia, da arte e da educação para o desenvolvimento humano e para a defesa de direitos das crianças e adolescentes.

Foi possível observar a importância do trabalho realizado pelo Cedeca Interlagos na região em que atua, baseado nos depoimentos que repetidamente apontaram a organização como maior referência em cultura e em espaço aberto para o jovem.

O Centro de Defesa tem conseguido despertar nestes adolescentes, além das noções de direitos e deveres, o sentido de "coletivo". Desse modo, percebe-se que, ao longo de sua história, a organização ganhou credibilidade junto a seu público, que se mostrou disponível e interessado em participar e colaborar com novos projetos.

Suas ações junto ao público, estabelecidas primeiramente a partir de relações culturais na rua, têm contribuído para o surgimento de inúmeros jovens artistas na região. Notou-se que a visibilidade do Centro de Defesa, bem como o impacto de suas atividades partiram principalmente de eventos realizados nas comunidades, tornando-o referência para outros centros de defesa e organizações locais. Mas a sua falta de atuação na rua nos últimos tempos sugere que a organização terá de realizar um novo planejamento, com a criação de estratégias para que potencialize as ações existentes e outras novas na área de defesa de direitos.

Os projetos de "Oficinas de fotografia e educação" estão sendo realizados há algum tempo, de forma que é possível observar que os impactos foram positivos e ainda prevalecem, mesmo passado algum tempo. Os entrevistados destacam como aprendizado mais importante e que extrapola os conhecimentos técnicos adquiridos durante os encontros, a questão do desenvolvimento do olhar e formação de uma visão crítica sobre o mundo. Demonstra-se, assim, a eficácia de projetos fotográficos, educativos e de comunicação que extrapolem os objetivos técnicos instrumentais e priorizem as relações humanas, estimulando o olhar sobre a sociedade.

Para além de uma iniciação técnica na fotografia, os participantes passaram a experimentar e enquadrar seu cotidiano de modo mais lúdico, detalhado e fotográfico. Com base nos depoimentos levantados, seus olhares se ressignificaram e suas visões se expandiram em vários aspectos com relação à fotografia 
comunicação \& educação • Ano XV|l| • número 1 • jan/jun 2013

e à sociedade. A partir dos diálogos estabelecidos no decorrer desta pesquisa, foi possível verificar que os participantes, além de se comunicarem por fotos e perceberem seu cotidiano mediado por instrumentos fotográficos, passaram também a reconstruir as imagens de si próprios. Contudo, o desenvolvimento de projetos fotográficos como estes que apresentamos pode, além de sugerir um possível caminho profissional, estimular o desenvolvimento de cidadãos com olhares menos ingênuos e mais conscientes de seus direitos e deveres.

\section{REFERÊNCIAS BIBLIOGRÁFICAS}

BACCEGA, Maria Aparecida. Educomunicação: comunicação/educação e a construção de nova variável histórica. In: COSTA, Maria Cristina Castilho; CITELLI, Adilson Odair (org.). Educomunicação: construindo uma nova área de conhecimento. São Paulo: Paulinas, 2011.

BARTHES, R. A câmara clara. Rio de Janeiro: Ed. Nova Fronteira, 1984.

BENJAMIN, Walter. A obra de arte na época de sua reprodutibilidade técnica. In: LIMA, Luiz Costa (org.). Teoria da cultura de massa. Rio de Janeiro: Paz e Terra, 1978.

CITELLI, A. Comunicação e educação: a linguagem em movimento. São Paulo: Editora Senac, 2000.

COSTA, Maria Cristina Castilho. Educação, imagem e mídias. São Paulo: Cortez, 2005 .

Ficção comunicação e mídias. São Paulo: Editora SENAC, 2002.

ESCOSTEGUY, Ana Carolina. Estudos culturais; uma produção. In: DA SILVA, Tomaz Tadeu (org.). O que é, afinal, estudos culturais? Belo Horizonte: Autêntica, 1999.

FREIRE, Paulo. A importância do ato de ler. São Paulo: Cortez, 1992

Conscientização: teoria e prática da libertação - uma introdução ao pensamento de Paulo Freire. 3. ed. São Paulo: Moraes, 1980.

Pedagogia do oprimido. Rio de Janeiro: Paz e Terra, 1970.

GADOTTI, Moacir. Educar para a sustentabilidade. 1. ed. São Paulo: Instituto Paulo Freire, 2008.

HALL, Stuart (Liv Sovik, org.). Da diáspora. Identidades e mediações culturais. Belo Horizonte/Brasília: UFMG/Unesco, 2003.

KOSSOY, B. Realidades e ficções na trama fotográfica. 4. ed. São Paulo: Ateliê Editorial, 2009.

. Fotografia e história. 2. ed. São Paulo: Ateliê Editorial, 2001. 
MACHADO, A. Máquina e imaginário: o desafio das poéticas tecnológicas. 3. ed. São Paulo: Editora da Universidade de São Paulo, 2001.

MARTÍN-BARBERO, Jesús. Globalização comunicacional e transformação cultural. In: Dênis de MORAES (org.). Por uma outra comunicação. Rio de Janeiro: Record, 2003.

. Dos meios às mediações. 2. ed. Rio de Janeiro: Ed. UFRJ, 2001.

Herendo el futuro. Pensar la educacion desde la comunicacion. Revista

Nómadas. n. 5. Departamento de Investigaciones - Universidad Central: Santafé de Bogotá, 1996.

MATTERLART, Armand; MATTELART, Michèle. História das teorias da comunicação. São Paulo: Loyola, 1998.

SCHAFF, A. A linguagem e conhecimento. Coimbra: Almedina, 1974.

SOARES, Ismar de Oliveira. Educomunicação. In: CITELLI, A.; COSTA, Maria Cristina Castilho (org). Educomunicação: um campo de mediações. São Paulo: Paulinas, 2011.

- Planejamento de projetos de gestão comunicativa. In: BACCEGA, Maria Aparecida; COSTA, Maria Cristina. Gestão da comunicação, projetos de intervenção. São Paulo: Paulinas, 2009.

- Caminhos da Gestão comunicativa como prática da educomunicação. In: BACCEGA. Maria Aparecida; COSTA, Maria Cristina. Gestão da comunicação: epistemologia e pesquisa teórica. São Paulo: Paulinas, 2009.

Teorias da comunicação e filosofia da educação: fundamentos epistemológicos da Educomunicação. São Paulo: Documento para a aula do Concurso de Titular da ECA USP, 2009.

SONTAG, S. Sobre fotografia. 5. ed. São Paulo: Companhia das Letras, 2004.

\section{REFERÊNCIAS SITIOGRÁFICAS}

UOL. O fotógrafo cego. Disponível em: <http://photos.uol.com.br/materias/ ver/51144>. Acesso em: maio 2012.

Site do filme Cidade de Deus. Disponível em: <http://cidadededeus.globo. com/>. Acesso em: abr. 2012. 
comunicação \& educação • Ano XVIII • número 1 • jan/jun 2013

\section{REFERÊNCIAS VIDEOGRÁFICAS}

CIDADE DE DEUS. Direção Fernando Meirelles, Kátia Lund. Roteiro Paulo Lins (romance), Bráulio Mantovani (roteiro). Duração 130 min. Brasil, Rio de Janeiro. Globo Filmes e O 2 Filmes, Brasil, 2002.

JANELA DA ALMA. Direção João Jardin, Walter Carvalho. Roteiro João Jardim, Walter Carvalho (Gênero documentário). Duração 73 min. Copacabana Filmes, Brasil, 2002. 